Published in final edited form as:

Clin Rev Bone Miner Metab. 2013 March ; 11(1): 11-16. doi:10.1007/s12018-012-9126-x.

\title{
Osteocalcin and the Regulation of Glucose Metabolism
}

\section{Adrian Vella and Rajiv Kumar}

\section{Abstract}

Uncarboxylated osteocalcin enhances insulin and adiponectin release and improves glucose tolerance in mice. Data in humans do not unequivocally support a role for osteocalcin in glucose homeostasis. Changes in the amount of uncarboxylated osteocalcin induced by vitamin $\mathrm{K}$ or warfarin treatment are not associated with changes in glucose and insulin concentrations. Interventional studies in humans, designed to detect small changes in insulin secretion and action attributable to changes in uncarboxylated osteocalcin, will be required to reliably detect effects of osteocalcin on glucose metabolism and to better understand its interaction with adiposity and adipokines.

\section{Keywords}

Osteocalcin; Undercarboxylated osteocalcin; Glucose; Insulin; Adiponectin

\section{Introduction}

Much as there has been a growing realization that adipose tissue is not merely a passive storage organ but one that plays an active role in metabolic regulation [1], so also there has been a longstanding acknowledgment of the fact that the skeletal system is not merely a passive structural organ [2]. Indeed, the skeleton is an active tissue which may play a role in the regulation of whole-body energetics. Bone is a very active tissue with constant remodeling to accommodate weight-bearing, growth and repair. This is accomplished by two antagonistic cell populations-osteoclasts which resorb mineralized bone while osteoblasts deposit osteoid which eventually becomes mineralized. The actions of osteoblasts and osteoclasts are closely coupled but their activity requires a constant supply of energy [3].

Obesity is a state characterized by a mismatch between energy expenditure and caloric intake leading to adipose deposition. Adipose tissue elaborates various chemokines that may actively regulate energy balance and to some extent bone metabolism. Certainly, excess avoirdupois also affects bone directly through skeletal loading [4]. The opposite scenario, as seen in anorexia nervosa, is associated with striking degrees of bone loss further illustrates the direct relationship between metabolism and skeletal integrity. Both of these examples illustrate the complex interplay between bone and metabolism, given the potential direct role of leptin on bone metabolism [5], suggesting effects of body weight beyond direct skeletal loading on bone integrity. Moreover, in anorexia nervosa, weight loss is typically associated with downregulation of sex steroid secretion as well as nutritional deficiencies, all of which have direct consequences on skeletal integrity [6]. 
As part of an effort to identify bone-derived signaling molecular that could influence metabolism, mouse models lacking osteoblast-specific molecules that are secreted extracellularly were screened for metabolic abnormalities [7]. This process identified mice deficient in osteocalcin who were hyperglycemic as a consequence of decreased $\beta$-cell mass and defective insulin secretion. In addition, these mice had increased fat mass and exhibited defective insulin action. In keeping with the observation that osteocalcin-deficient mice have defective $\beta$-cell function, osteocalcin infusion in wild-type mice causes insulin secretion and improves insulin action thereby improving glucose tolerance [8].

Osteocalcin is a peptide secreted by osteoblasts and is present within the bone matrix (it forms $1-2 \%$ of bone matrix protein) and within the circulation [9]. It has three $\gamma$ carboxyglutamic residues (one of which is partially modified) that bind calcium. Osteocalcin $\gamma$-carboxylation is vitamin $\mathrm{K}$ dependent and may affect the action of osteocalcin on glucose metabolism raising the possibility that modulators of osteocalcin $\gamma$ - carboxylation could be used in the treatment of diabetes [10]. In this review, we will examine the in vitro and in vivo evidence for osteocalcin as a regulator of glucose metabolism and discuss what additional evidence is required to accept this role for osteocalcin.

\section{Physiologic Processes Maintaining Glucose Tolerance in Vivo}

Glucose concentrations are closely regulated in health because this simple carbohydrate is the main fuel used by various organs [11]. Conversely, prolonged hyperglycemia as observed in diabetes leads to macro- and microvascular complications such as ischemic heart disease, retinopathy, and nephropathy [12]. Adults with diabetes have cardiac mortality rates about 2-4 times higher than adults without diabetes and a risk for stroke that is 2-4 times that of individuals without diabetes. Greater than $60 \%$ of non-traumatic lowerlimb amputations occur in people with diabetes [13].

Diabetes is defined by the presence of fasting glucose concentrations $>126 \mathrm{mg} / \mathrm{dl}$ or glucose concentrations $>200 \mathrm{mg} / \mathrm{dl} 2 \mathrm{~h}$ after a $75 \mathrm{~g}$ oral glucose tolerance test. Since normal glucose metabolism is defined by a fasting glucose $<100 \mathrm{mg} / \mathrm{dl}$ and normal glucose tolerance is defined by glucose concentrations $<140 \mathrm{mg} / \mathrm{dl}, 2 \mathrm{~h}$ after a $75 \mathrm{~g}$ oral glucose tolerance test this enables definition of an intermediate prediabetic state characterized by impaired fasting glucose and/or impaired glucose tolerance [13]. These prediabetic states are characterized by impaired insulin secretion and action and an increased risk of progression to type 2 diabetes $[14,15]$. Post-challenge glucose concentrations are a better predictor of diabetes risk as they are a better measure of $\beta$-cell function (and other homeostatic mechanisms) than are fasting glucose concentrations [16].

Glucose tolerance depends first and foremost on insulin secretion, i.e., the ability of the $\beta$ cells in the pancreatic islets to respond to hyperglycemia in an appropriate and timely fashion. The timing of the response rather than the magnitude (which is delayed and blunted early in the course of diabetes but not actually deficient over the course of a tolerance test) that is qualitatively different in diabetic versus non-diabetic individuals [17]. It is important to differentiate between physiologic versus non-physiologic stimuli when assessing insulin secretion. For example, the intravenous glucose tolerance test results in the rapid systemic 
appearance of glucose (a phenomenon not observed with oral challenges) and insulin secretion in two different phases. The first phase $\left(\varnothing_{1}\right)$ represents insulin already present in insulin granules, while the second phase $\left(\emptyset_{2}\right)$ represents de novo synthesis of insulin. Such distinct phases of insulin secretion are not observed with oral challenges [18].

Hyperglycemic clamps are a variation of the intravenous glucose tolerance test in which hyperglycemia is maintained for prolonged periods of time at relatively supraphysiologic concentrations (e.g., $300 \mathrm{mg} / \mathrm{dl}$ ) and is an attempt to measure $\beta$-cell reserve, i.e., maximal insulin secretory capacity rather than function in situations relevant to normal physiology [19]. Another example is the glucagon-stimulation test which utilizes a pharmacologic stimulus delivered in a non-physiologic manner to measure $\beta$-cell integrity. Although this may be useful in classifying people with diabetes, it has little relevance to the ability of such islets to respond to physiologic stimuli such as meals [20]. Another problem with intravenous tests is that they do not test the integrity of the incretin response-a mechanism that also contributes to the maintenance of glucose tolerance in vivo [21].

Insulin action is the ability of insulin to stimulate glucose uptake and suppress endogenous glucose production. Insulin secretion can be related to the prevailing insulin action as a disposition index-an expression of the hyperbolic relationship between insulin secretion and action at a given degree of glucose tolerance. The disposition index is perhaps a better descriptor of an individual's (physiologic) $\beta$-cell function that indices derived purely from peripheral measures of insulin concentrations alone [22].

Another important but under-looked aspect to the maintenance of glucose tolerance is the systemic availability of insulin. Insulin is secreted into the portal circulation and is partially cleared by the liver prior to its appearance in the portal circulation [23]. There is some evidence that hepatic insulin clearance is altered in prediabetes and diabetes, suggesting that this process is not passive and may be modulated by impaired insulin action and/or impaired insulin secretion [24]. Glucose effectiveness is the ability of glucose per se to stimulate its own uptake and suppress its own release and is also defective in people with established diabetes $[25,26]$.

When calories are delivered orally, the resting stomach volume, the capacity of the stomach to accommodate (by actively increasing its volume via a vagally mediated process) and empty all play a role in determining the systemic appearance of glucose [27]. Caloric liquids appear much more rapidly in comparison to solids and the rate of appearance is affected by fasting gastric volume [28]. However, no differences in the rates of gastric emptying have been consistently demonstrated across the spectrum of glucose tolerance [29]. Differences in gastric emptying are unlikely to play a role in the pathogenesis of type 2 diabetes. More importantly, the appearance of nutrients in the duodenum has been associated with neuroenteric and enteroendocrine signals collectively known as the "incretin effect" which stimulates insulin secretion to a greater degree than when that stimulus is administered intravenously [30]. The 2 principal incretin hormones Glucose-dependent Insulinotropic Polypeptide (GIP) and Glucagon-Like Peptide-1 (GLP-1) are potent insulin secretagogues which also suppress a-cell secretion of glucagon [21]. Decreased secretion of these hormones is not apparent in prediabetes, and this mechanism does not appear to contribute 
significantly to the pathogenesis of type 2 diabetes [31]. On the other hand, diminished responsiveness of the $\beta$-cell (in terms of insulin secretion) to these hormones is apparent in prediabetes and diabetes [32]. Whether this is a defect specific to these secretagogues or is part of a global decrease in $\beta$-cell responsiveness to multiple such stimuli remains to be ascertained.

\section{Osteocalcin and Glucose Metabolism}

As described in the introduction, mice deficient in osteocalcin are hyperglycemic and have increased adiposity [7]. They are characterized by defective insulin secretion and decreased $\beta$-cell mass. In islet perfusion experiments, it acts as an insulin secretagogue and increases insulin gene expression in cultured islets [33]. This is congruent with the observation that infusion of osteocalcin into wild-type mice causes increased insulin secretion and enhances glucose tolerance [8]. Osteocalcin $\gamma$-carboxylation transforms glutamate residues into $\gamma$ carboxyglutamate (Gla) residues thereby conferring high-affinity for hydroxyapatite. This explains the abundance of the carboxylated form of osteocalcin in bone [9]. However, both fully carboxylated and undercarboxylated forms of osteocalcin are found in the circulation raising the possibility that one or both isoforms are mediators of the observed actions of osteocalcin.

Such questions are not addressed by the $O c n^{-l-}$ mouse, and it is conceivable that the observed effects of infused recombinant (uncarboxylated) osteocalcin may be explained by subsequent in vivo carboxylation. Osteocalcin decarboxylation is inhibited by a tyrosine phosphatase ESP. Mice deficient in $\operatorname{ESP}\left(E s p^{-l_{-}}\right)$have increased undercarboxylated osteocalcin (ucOC) and are lean with enhanced insulin sensitivity and increased glucose tolerance [7]. This phenotype is also observed in mice with osteoblast-specific deletions of $E s p$. Interestingly, $E s p^{-1}$-mice have increased bone resorption due to increased osteoclastic activity, liberating carboxylated osteocalcin (cOC) from the bone matrix [34]. Moreoever, cOC can be decarboxylated in an acidic milieu present at the sites of bone resorption [35]. The phenotype seen in these mice can be normalized by the introduction of one mutant Ocn allele, which normalizes ucOC concentrations [34], or by inhibition of bone resorption using a bisphosphonate.

Since ESP is a tyrosine phosphatase, it is reasonable to hypothesize that the insulin receptor may be a substrate for this enzyme. Indeed, mice with an osteoblast-specific deletion of the insulin receptor are glucose intolerant [36], and the insulin receptor induces Ocn expression and decreases osteoprotegerin secretion [34]. Osteoprotegerin restrains osteoclast function, and therefore, insulin receptor signaling facilitates the secretion of osteocalcin and its subsequent decarboxylation. Given the effects of ucOC on insulin secretion, this data would suggest the presence of a feed-forward loop so that osteocalcin favors insulin secretion and enhanced osteoblast insulin signaling favors increased elaboration of ucOC.

We previously alluded to the effects of leptin on bone metabolism. Leptin is an adipokine that negatively regulates appetite and stimulates sympathetic output which inhibits bone formation via the $\beta_{2}$-adrenergic receptor [37]. It also increases the production of RANK ligand which has effects opposite to those of osteoprotegerin on osteoclasts thereby 
promoting resorption. Although this should favor ucOC release, activation of bone $\beta_{2}$ adrenergic receptors increases ESP expression and osteoprotegerin secretion. Indeed, mice with impaired $\beta_{2}$ adrenergic signaling $\left(A d r B 2^{-l-}\right.$ ) have low ucOC and are glucose intolerant [33].

\section{Osteocalcin and Glucose Metabolism-Evidence in Humans}

There are several implication from this basic research some of which have been examined in humans. Given that glutamate carboxylation or decarboxylation is key to the metabolic role of osteocalcin (at least in rodents) and that carboxylation is vitamin $\mathrm{K}$ dependent, an obvious question that arises is whether the ratio of $\mathrm{ucOC}$ to $\mathrm{COC}$ is altered by Coumadin or Vitamin $\mathrm{K}$ administration and whether such alterations affect glucose metabolism. The second question pertains to the relationship between insulin action and insulin secretion. In healthy humans, as insulin action decreases (e.g., due to weight gain), insulin secretion rises to compensate and maintain glucose tolerance. It is unclear as to how a change in insulin action either through weight changes (which may affect leptin secretion) or through pharmacologic means alters ucOC concentrations. Finally, given the effect of bone resorption on ucOC, it is unclear whether antiresorptive agents such as bisphosphonates alter ucOC and consequently, insulin secretion and action.

Binkley et al. [38] have demonstrated that phylloquinone (vitamin K1) supplementation reduces concentrations of serum under $\gamma$-carboxylated osteocalcin (ucOC) in healthy young and elderly adults, and Bach et al. [39] have demonstrated that low-dose warfarin substantially increases ucOC serum concentrations without affecting prothrombin time or other clotting parameters. To assess whether changes in ucOC are associated with changes in serum glucose or insulin concentrations in humans, we examined total osteocalcin, ucOC and glucose and insulin concentrations in women who had been treated with phylloquinone for 1 year. Reductions in ucOC would be predicted to worsen glucose homeostasis since infusions of uncarboxylated osteocalcin in mice have been shown to improve glucose homeostasis and increase insulin gene expression in isolated islets [8].

Six and 12 months' of phylloquinone administration produced a 200\% decrease in ucOC concentrations. However, despite these dramatic changes in ucOC concentration, glucose and insulin concentrations remained unchanged [40]. Although this study did not demonstrate an increase in serum glucose concentrations following a reduction in ucOC concentrations and suggests that ucOC is not involved in glucose homeostasis in humans, there are limitations to this study that should be kept in mind. First, serum glucose and serum insulin concentrations were studied only in the basal fasting state before and after phylloquinone administration. It is possible that changes in glucose disposition and insulin concentrations might be present in the ucOC-deficient state following the administration of a glucose load. Also, we are unaware of hypoglycemia following the institution of warfarin thereapy-which would inhibit the $\gamma$-carboxylation of vitamin K-dependent proteins [41]-and thereby lead to a significant rise in ucOC concentrations [39].

In the Baltimore Longitudinal Study of Aging (BLSA), linear regression models were used to test independent associations of leptin, osteocalcin, and adiponectin with insulin secretion 
and action. Total osteocalcin was measured and found to be negatively associated with insulin resistance as measured by the Homeostasis Model Assessment of Insulin Resistance (HOMA-IR) after adjusting for age, sex and BMI. There was no effect on insulin secretion as measured by a qualitative method dependent on pheripheral insulin concentrations (which as discussed previously reflect both secretion and clearance) [42]. This is in contrast to other data showing an association between osteocalcin and insulin secretion measured by an intravenous glucose tolerance test (a situation with no incretin contribution to insulin secretion) in 149 subjects [43]. Another smaller study has shown a positive association of osteocalcin with insulin secretion measured with an oral glucose challenge which might suggest that osteocalcin does not modulate the effect of incretins on $\beta$-cell secretion [44].

Beyond such observations there are multiple studies demonstrating an inverse correlation of circulation osteocalcin with BMI and other markers of adiposity as well as with the presence of diabetes. Das et al. reported an association of variants in BGLAP (Bone $\gamma$-carboxy Glutamate Protein gene which synthesizes osteocalcin in humans) with diabetes in AfricanAmericans [45] but that was not replicated in larger well-powered Genome-Wide Association Studies (GWAS) [46]. Most of these studies are observational and crosssectional in nature and can therefore only show association not causality. Interventional studies designed to detect small changes in insulin secretion and action attributable to changes in ucOC will be required to reliably detect effects of osteocalcin on glucose metabolism and better understand its interaction with adiposity and adipokines in humans.

\section{Acknowledgments}

Supported by NIH grants DK78646 and DK82396 (to Adrian Vella) and AR058003 and AR060869 (to Rajiv Kumar) and a grant from the Ralph and Marion C. Falk Foundation (to Rajiv Kumar).

\section{References}

1. Maury E, Brichard SM. Adipokine dysregulation, adipose tissue inflammation and metabolic syndrome. Mol Cell Endocrinol. 2010; 314:1-16. [PubMed: 19682539]

2. Ducy P. The role of osteocalcin in the endocrine cross-talk between bone remodelling and energy metabolism. Diabetologia. 2011; 54:1291-7. [PubMed: 21503740]

3. Eastell R. Treatment of postmenopausal osteoporosis. N Engl J Med. 1998; 338:736-46. [PubMed: 9494151]

4. Reid IR. Relationships between fat and bone. Osteoporos Int. 2008; 19:595-606. [PubMed: 17965817]

5. Kawai M, Devlin MJ, Rosen CJ. Fat targets for skeletal health. Nat Rev Rheumatol. 2009; 5:36572. [PubMed: 19468288]

6. Misra M, Klibanski A. Evaluation and treatment of low bone density in anorexia nervosa. Nutr Clin Care. 2002; 5:298-308. [PubMed: 12557813]

7. Lee NK, Sowa H, Hinoi E, Ferron M, Ahn JD, Confavreux C, Dacquin R, Mee PJ, McKee MD, Jung DY, Zhang Z, Kim JK, Mauvais-Jarvis F, Ducy P, Karsenty G. Endocrine regulation of energy metabolism by the skeleton. Cell. 2007; 130:456-69. [PubMed: 17693256]

8. Ferron M, Hinoi E, Karsenty G, Ducy P. Osteocalcin differentially regulates beta cell and adipocyte gene expression and affects the development of metabolic diseases in wild-type mice. Proc Natl Acad Sci USA. 2008; 105:5266-70. [PubMed: 18362359]

9. Hauschka PV, Lian JB, Cole DE, Gundberg CM. Osteocalcin and matrix Gla protein: vitamin Kdependent proteins in bone. Physiol Rev. 1989; 69:990-1047. [PubMed: 2664828] 
10. Kumar R, Vella A. Carbohydrate Metabolism and the Skeleton: Picking a Bone with the (beta)Cell. J Clin Endocrinol Metab. 2011; 96:1269-71. [PubMed: 21346061]

11. Dinneen S, Gerich J, Rizza R. Carbohydrate metabolism in non-insulin-dependent diabetes mellitus. N Engl J Med. 1992; 327:707-13. [PubMed: 1495524]

12. The effect of intensive treatment of diabetes on the development and progression of long-term complications in insulin-dependent diabetes mellitus. The Diabetes Control and Complications Trial Research Group. N Engl J Med. 1993; 329:977-986. [PubMed: 8366922]

13. Report of the Expert Committee on the Diagnosis and Classification of Diabetes Mellitus. Diabetes Care. 1997; 20:1183-1197. [PubMed: 9203460]

14. Bock G, Dalla Man C, Campioni M, Chittilapilly E, Basu R, Toffolo G, Cobelli C, Rizza R. Pathogenesis of pre-diabetes: mechanisms of fasting and postprandial hyperglycemia in people with impaired fasting glucose and/or impaired glucose tolerance. Diabetes. 2006; 55:3536-49. [PubMed: 17130502]

15. Dinneen SF, Maldonado D III, Leibson CL, Klee GG, Li H, Melton LJ III, Rizza RA. Effects of changing diagnostic criteria on the risk of developing diabetes. Diabetes Care. 1998; 21:1408-13. [PubMed: 9727885]

16. Abdul-Ghani MA, Stern MP, Lyssenko V, Tuomi T, Groop L, Defronzo RA. Minimal contribution of fasting hyperglycemia to the incidence of type 2 diabetes in subjects with normal 2-h plasma glucose. Diabetes Care. 2010; 33:557-61. [PubMed: 20007945]

17. Basu A, Alzaid A, Dinneen S, Caumo A, Cobelli C, Rizza RA. Effects of a change in the pattern of insulin delivery on carbohydrate tolerance in diabetic and nondiabetic humans in the presence of differing degrees of insulin resistance. J Clin Invest. 1996; 97:2351-61. [PubMed: 8636416]

18. Caumo A, Luzi L. First-phase insulin secretion: does it exist in real life? Considerations on shape and function. Am J Physiol Endocrinol Metab. 2004; 287:E371-85. [PubMed: 15308473]

19. Sathananthan A, Man CD, Micheletto F, Zinsmeister AR, Camilleri M, Giesler PD, Laugen JM, Toffolo G, Rizza RA, Cobelli C, Vella A. Common genetic variation in GLP1R and insulin secretion in response to exogenous GLP-1 in nondiabetic subjects: a pilot study. Diabetes Care. 2010; 33:2074-6. [PubMed: 20805279]

20. Service FJ, Rizza RA, Zimmerman BR, Dyck PJ, O'Brien PC, Melton LJ III. The classification of diabetes by clinical and C-peptide criteria. A prospective population-based study. Diabetes Care. 1997; 20:198-201. [PubMed: 9118774]

21. Drucker DJ, Nauck MA. The incretin system: glucagon-like peptide-1 receptor agonists and dipeptidyl peptidase-4 inhibitors in type 2 diabetes. Lancet. 2006; 368:1696-705. [PubMed: 17098089]

22. Cobelli C, DallaMan C, Sparacino G, Magni L, De Nicolao G, Kovatchev BP. Diabetes: models, signals, and control. IEEE Rev Biomedical Eng. 2009; 2:54-96.

23. Meier JJ, Veldhuis JD, Butler PC. Pulsatile insulin secretion dictates systemic insulin delivery by regulating hepatic insulin extraction in humans. Diabetes. 2005; 54:1649-56. [PubMed: 15919785]

24. Sathananthan A, Man CD, Zinsmeister AR, Camilleri M, Rodeheffer RJ, Toffolo G, Cobelli C, Rizza RA, Vella A. A concerted decline in insulin secretion and action occurs across the spectrum of fasting and post-challenge glucose concentrations. Clin Endocrinol (Oxf). 2011

25. Basu A, Caumo A, Bettini F, Gelisio A, Alzaid A, Cobelli C, Rizza RA. Impaired basal glucose effectiveness in NIDDM: contribution of defects in glucose disappearance and production, measured using an optimized minimal model independent protocol. Diabetes. 1997; 46:421-32. [PubMed: 9032098]

26. Basu A, Rizza RA. Glucose effectiveness: measurement in diabetic and nondiabetic humans. Exp Clin Endocrinol Diabetes. 2001; 109(Suppl 2):S 157-65.

27. Delgado-Aros S, Cremonini F, Castillo JE, Chial HJ, Burton DD, Ferber I, Camilleri M. Independent influences of body mass and gastric volumes on satiation in humans. Gastroenterology. 2004; 126:432-40. [PubMed: 14762780]

28. Camilleri M. Integrated upper gastrointestinal response to food intake. Gastroenterology. 2006; 131:640-58. [PubMed: 16890616] 
29. Kim DY, Camilleri M, Murray JA, Stephens DA, Levine JA, Burton DD. Is there a role for gastric accommodation and satiety in asymptomatic obese people? Obes Res. 2001; 9:655-61. [PubMed: 11707531]

30. Mclntyre N, Holdsworth CD, Turner DS. New interpretation of oral glucose tolerance. Lancet. 1964; 2:20-1.

31. Nauck MA, Vardarli I, Deacon CF, Hoist JJ, Meier JJ. Secretion of glucagon-like peptide-1 (GLP-1) in type 2 diabetes: what is up, what is down? Diabetologia. 2011; 54:10-8. [PubMed: 20871975]

32. Fritsche A, Stefan N, Hardt E, Haring H, Stumvoll M. Characterisation of beta-cell dysfunction of impaired glucose tolerance: evidence for impairment of incretin-induced insulin secretion. Diabetologia. 2000; 43:852-8. [PubMed: 10952457]

33. Hinoi E, Gao N, Jung DY, Yadav V, Yoshizawa T, Myers MG Jr, Chua SC Jr, Kim JK, Kaestner $\mathrm{KH}$, Karsenty G. The sympathetic tone mediates leptin's inhibition of insulin secretion by modulating osteocalcin bioactivity. J Cell Biol. 2008; 183:1235-42. [PubMed: 19103808]

34. Ferron M, Wei J, Yoshizawa T, Del Fattore A, DePinho RA, Teti A, Ducy P, Karsenty G. Insulin signaling in osteoblasts integrates bone remodeling and energy metabolism. Cell. 2010; 142:296308. [PubMed: 20655470]

35. Engelke JA, Hale JE, Suttie JW, Price PA. Vitamin K-dependent carboxylase: utilization of decarboxylated bone Gla protein and matrix Gla protein as substrates. Biochim Biophys Acta. 1991; 1078:31-34. [PubMed: 2049381]

36. Fulzele K, Riddle RC, DiGirolamo DJ, Cao X, Wan C, Chen D, Faugere MC, Aja S, Hussain MA, Bruning JC, Clemens TL. Insulin receptor signaling in osteoblasts regulates postnatal bone acquisition and body composition. Cell. 2010; 142:309-19. [PubMed: 20655471]

37. Ducy P, Amling M, Takeda S, Priemel M, Schilling AF, Beil FT, Shen J, Vinson C, Rueger JM, Karsenty G. Leptin inhibits bone formation through a hypothalamic relay: a central control of bone mass. Cell. 2000; 100:197-207. [PubMed: 10660043]

38. Binkley NC, Krueger DC, Engelke JA, Foley AL, Suttie JW. Vitamin K supplementation reduces serum concentrations of under-gamma-carboxylated osteocalcin in healthy young and elderly adults. Am J Clin Nutr. 2000; 72:1523-8. [PubMed: 11101481]

39. Bach AU, Anderson SA, Foley AL, Williams EC, Suttie JW. Assessment of vitamin K status in human subjects administered "minidose" warfarin. Am J Clin Nutr. 1996; 64:894-902. [PubMed: 8942414]

40. Kumar R, Binkley N, Vella A. Effect of phylloquinone supplementation on glucose homeostasis in humans. Am J Clin Nutr. 2010; 92:1528-32. [PubMed: 20881072]

41. Suttie JW, Hageman JM. Vitamin K-dependent carboxylase. Development of a peptide substrate. J Biol Chem. 1976; 251:5827-30. [PubMed: 965394]

42. Gravenstein KS, Napora JK, Short RG, Ramachandran R, Carlson OD, Metter EJ, Ferrucci L, Egan JM, Chia CW. Cross-sectional evidence of a signaling pathway from bone homeostasis to glucose metabolism. J Clin Endocrinol Metab. 2011; 96:E884-90. [PubMed: 21389141]

43. Fernandez-Real JM, Izquierdo M, Ortega F, Gorostiaga E, Gomez-Ambrosi J, Moreno-Navarrete JM, Fruhbeck G, Martinez C, Idoate F, Salvador J, Forga L, Ricart W, Ibanez J. The relationship of serum osteocalcin concentration to insulin secretion, sensitivity, and disposal with hypocaloric diet and resistance training. J Clin Endocrinol Metab. 2009; 94:237-45. [PubMed: 18854399]

44. Bao YQ, Zhou M, Zhou J, Lu W, Gao YC, Pan XP, Tang JL, Lu HJ, Jia WP. Relationship between serum osteocalcin and glycaemic variability in Type 2 diabetes. Clin Exp Pharmacol Physiol. 2011; 38:50-4. [PubMed: 21083700]

45. Das SK, Sharma NK, Elbein SC. Analysis of osteocalcin as a candidate gene for type 2 diabetes (T2D) and intermediate traits in Caucasians and African Americans. Dis Markers. 2010; 28:281-6. [PubMed: 20592451]

46. Stolerman ES, Florez JC. Genomics of type 2 diabetes mellitus: implications for the clinician. Nat Rev Endocrinol. 2009; 5:429-36. [PubMed: 19564886] 